Статья с открытым доступом под лицензией CC BY-NC-ND (https://creativecommons.org/licenses/by-nc-nd/3.0/)

Материалы Международной практической интернет-конференции «Актуальные проблемы науки»

Выпуск II, ноябрь 2019

ISBN 978-601-323-144-0

https://doi.org/10.31643/2019.029

Бекенова Жибек Амантаевна

КазНПУ им. Абая, Республика Казахстан

E-mail: zh.bekenova@mail.ru

\title{
Психолого-педагогические условия формирования культуры взаимодействия школы с родителями в Казахстане
}

\begin{abstract}
Абстракт. На современном этапе вопросам взаимодействия семьи и школы, формированию культуры, ее психолого-педагогическим условиям уделяется большое внимание. Наряду с образованием и воспитанием, школа, как очаг доверия для многих детей и родителей, занимается просвещением всех участников образовательного процесса. Чаще всего родительские собрания, Школы для родителей посещают семьи с активной гражданской позицией, с высоким или достаточным уровнем культуры, которые находят время, чтобы быть рядом и вовремя выслушать своего ребенка, умеют любить своих детей, интересуются делами в школе, находятся в тесном контакте с классным руководителем. Но их процент не является высоким. Анализируя сложившиеся социальнопедагогические ситуации, стало ясным, что повышения педагогической культуры родителей является одной из важных насущных проблем. В новых социально-экономических условиях традиционные формы работы педагогический правовой всеобуч, педагогическое просвещение в виде лекций не являются эффективными. Требует внимания новые формы и методы работы и сотрудничества семьи и школы, обмен опытом психологопедагогической работы с родителями в современной школе.
\end{abstract}

Ключевые слова: воспитание, школа, родители, семья, педагогическая культура.

\section{Введение}

Мы стоим на пороге того времени, когда необходимо переосмыслить сотрудничество семьи и школы, когда родители начинают становиться активными участниками образовательного процесса, но все же остаются недостаточно используемым ресурсом в образовательных учреждениях. Просвещение семьи в вопросах обучения и воспитания ребенка является одной из важных функций государства. Теоретической основой исследования является общая теория психолого-педагогической культуры семьи (И. В. Гребенников, П. Ф. Лесгафт, В. А. Сухомлинский, А. С. Макаренко, В. Я. Титаренко и др.). Просвещение семьи в вопросах обучения и воспитания ребенка в современных условиях реализуется через самообразование родителей, платные образовательные услуги специалистов, а также, что стало особенно популярным в последние годы, образовательные организации, где обучается ребенок. Формирование у родителей необходимой педагогической основы благодаря различным формам просветительской деятельности - одна из приоритетных задач школьного образования. Модернизация образования предполагает повышение семейных ценностей, как одного из важнейших аспектов воспитания, что отражено в основных документах образования, в том числе в Концептуальных основах воспитания в условиях реализации Программы «Рухани жаңғыру» на 2019-2024 годы [1]. Этот документ направлен на реализацию Государственной программы развития образования на 2016-2019 г.г., Послания Президента народу Казахстана от октября 2018г. Так, согласно ст.27 Конституции Республики Казахстан брак и семья, материнство, отцовство и детство находятся под защитой государства.Данные документы подтверждают необходимость переосмысления статуса семьи в образовании, совершенствования системы работы с родителями, в частности, в вопросах формирования педагогической культуры семьи с целью развития ее педагогического потенциала. В связи с глобальными изменениями мира, появлением новых технологий и большого объема различных гаджетов на рынке, человеческая мысль не успевает адаптироваться, сделать выбор, соответственно, 
подростки, у которых еще не сформирован стержень, с неокрепшей психикой остаются наедине со своими проблемами, и чаще с виртуальным миром. Многие взрослые, несмотря на знания основ психологии, оправдывая себя занятостью, не задумываются об опасности негативных сайтов и низкой культуры социальных сетей. При обращении в психологическую службу или к администрации школы, они чаще всего находят ответы на свои насущные вопросы. Работают Советы родительской общественности: традиционные родительские комитеты школы, класса, Попечительские Советы, Советы аксакалов и Советы отцов. Вместе с ними работают Школы для молодых родителей, в котором также задействованы многодетные родители, опытные мамы и папы, сумевшие поделиться своим опытом воспитания подростков и которые являются огромным ресурсом, нерастраченным потенциалом в деле воспитания подрастающего поколения. Из опыта работы можно сказать о Школе по созданию доверительных отношений между родителями и детьми «Сыйластық мекені», в работе которой принимают участие и образцовые родители, которым есть что сказать другим.

На сегодняшний день шагом вперед в деле просвещения родителей была рекомендованная Министерством образования и науки и проведенная в сентябре и октябре месяцах 2018 года Республиканская конференция «КАЗАХСТАНСКИЕ РОДИТЕЛИ ХХІ ВЕКА: СТАНЬ ПРИМЕРОМ СВОЕМУ РЕБЕНКУ». Повестка дня была расписана на двух языках: государственном и русском. Проработаны были все вопросы, видеоматериалы, которые включали все актуальные вопросы. Но одним из важных факторов, на наш взгляд было то, что родителей учащихся разделили по возрастным категориям и по классам, дав сетку-расписание по дням. Все ми понимаем, нередко подготовленное содержательное родительское собрание охватывает от 8 до 43 \% родителей и даже в некоторых случаях носит формальный характер. Вышеназванная родительская конференция, стала первым примером не только для родителей, но и педагогической общественности, как рационально использовать интерактивные формы и методы работы, но и самое главное, обратить внимание родителей на актуальные вопросы и на высокую результативность сотрудничества семьи и школы. Тем самым была оказана психолого-педагогическая помощь родителям учащихся с 1 по 11 класс и многие родители смогли получить ответы на свои вопросы. Активность участия родителей в конференции в некоторых регионах республики составила от $80 \%$ до $95 \%$ [2].

Актуализация семьи как ресурса сферы образования обуславливает необходимость повышения уровня педагогической культуры, а значит компетентности родителя. Педагогическая компетентность это совокупность педагогических качеств родителя, основанная на педагогическом знании, опыте, обеспечивающая возможность быть не только родителем (биологическим воспроизводителем), но и воспитателем высоконравственной личности, полезной для общества.

Именно в семье обеспечивается воспитание, закладываются и важнейшие качества личности. Несомненно, в ней ребенок получает первые представления о мире: здесь формируется понятия, взгляды, чувства, здесь образуется определенный багаж привычек, навыков и нравственных качеств, который ребенок возьмет с собой в жизнь. Только в семье можно создать культуру родственных отношений, освоить важнейшие социальные роли, сформировать культуру, обогатить нравственный опыт, осуществить половое воспитание детей, подготовить их к будущей семейной жизни. Которую в будущем как истину он будет воспроизводить уже в своей семье. Ведь только семья закладывает разумную организацию жизни ребенка и помогает усвоить опыт старшего поколения и накопить индивидуальный опыт.

Празднования в этом году 30-летия создания Конвенции о правах ребенка, ратифицированный Казахстаном 25 лет назад напоминают миру о правах ребенка. Все мероприятия, в рамках Республиканской и Международной акции по профилактике жестокости и насилия направлены на участие в них и родителей. Закон об образовании обязывает семью создавать необходимые условия для детей, их своевременного получения образования и профессиональной подготовки, , прививать им трудовые навыки, бережное отношение к общественной собственности, проявлять особую заботу о здоровье ребенка, о его полноценном физическом и нравственном развитии . Уклад семейной жизни влияет на формирование нравственности и общественной направленность личности подростка, на его ценностные ориентации и психологические установки. Ведь детство является важнейшим периодом человеческой жизни, которая проживается ребенком и оставляет след в будущей жизни [3].

Целью исследования является то, насколько фактически семейные ценности являются приоритетом у родителей и насколько ребенок является счастливым субъектом воспитания или глубоко несчастным, одиноким подростком, не нашедшего тепла в собственной семье. Школа является отражением общества. К сожалению, есть родители, которые полностью не осознавая свою ответственность перед детьми, даже не пытаются решить проблемы и не ищут пути решения. Вопросы 
взаимодействии школы и семьи имеют давние традиции, но в связи с падением нравов, снижению семейных ценностей у современных родителей главными задачами педагогов являются следующие:

$>$ обучение родителей использованию различных инструментов: приемам и способам обучения взрослых и детей, членов семьи;

$>$ оказание помощи не только социально-неадаптированным семьям, но и любым нуждающимся в психолого- педагогической помощи в осознании позитивных и негативных ситуаций.

Успешность достижений ребенка и его социально-психологическая защищенность зависят от того, кто и как влияет на его развитие.

ТОО «Институт Семейного Воспитания», / генеральный директор Евдокимова С.Л./, является главным разработчиком Республиканской конференции «КАЗАХСТАНСКИЕ РОДИТЕЛИ ХХІ ВЕКА: СТАНЬ ПРИМЕРОМ СВОЕМУ РЕБЕНКУ»., понимая, что развитие системЫ образования тесно связано с современными тенденциями общественного развития взял за основу принципы открытости и непрерывности. Образовательная деятельность становится важнейшим компонентом развития общества. Происходит нарастающее, существенное информационное пересечение сферы образования и социальноэкономической сферы жизни [4].

В 2019 году Институтом Семейного Воспитания (г. Нур-Султан) по поручению Министерства Образования и Науки Казахстана была разработана программа курса лекций онлайн обучения классных руководителей.

Целью данной программы является - вооружить знаниями педагогов , необходимыми для повышения эффективности взаимодействие школы с родителями учащихся.

Семья остается колыбелью личности человека, в семье развиваются эмоциональная и волевая сферы личности ребенка, усваиваются нормы морали и нравственности, прививается трудолюбие, закладываются основы дисциплинированности и ответственности.

Родительство - это очень непростой труд, зачастую родители чувствуют себя беспомощными и опускают руки - им не хватает педагогической грамотности, они нуждаются в квалифицированных советах по тем проблемам, с которыми они сталкиваются.

Из этого следует, что подготовка высококвалифицированных педагогических кадров - одна из основных задач национальной системы образования Казахстана.

В условиях постоянно меняющейся жизни общества, развивающейся системы образования, преподаватель должен быть готов к непрерывному совершенствованию и повышению своей квалификации. А обществом должны быть созданы условия, при которых педагог может реализовать свою потребность в постоянном обучении и развитии.

В рамках повышения квалификации классные руководители изучали материалы проекта программы «Счастливая семья»? Постараюсь объяснить и показать. Задача учителя дать знания, развить в ребенке жажду к познанию нового, объяснить пути саморазвития. То есть быть одним из первых проводников на жизненном пути человека. Но мы все понимаем, что совершенно недостаточно только хорошо обучить детей, дать им глубокие знания.

Выражение, «Нужно не только хорошо обучить, но и правильно воспитать» ставшее уже давно аксиомой, должно из теоретического постулата перейти в качественно-практический.

Вот здесь и выходит на первый план задача всемерной помощи семье с целью повышения ее воспитательного потенциала, поскольку педагогическая некомпетентность родителей, психологический дискомфорт и нестабильная эмоциональная атмосфера в семье могут привести к формированию у молодежи неадекватных и негативных жизненных установок.

Воспитание родителей, повышение их уровня педагогической культуры перестает быть частным делом отдельных семей, а приобретает масштаб государственного значения.

В вопросе сотрудничества семьи со школой важнейшим звеном являются классные руководители.

Именно классные руководители видят всю полноту картины пребывания ребенка в школе знают и его успеваемость, и его поведение - a, значит, могут наилучшим образом направить родителей в их воспитательных усилиях, способствуя повышению качества семейного воспитания.

Решение этих задач требует от классных руководителей кропотливой, последовательной работы по налаживанию сотрудничества с семьями учащихся, а также знаний по основным вопросам семейного воспитания [5]. Знания нужны для того, чтобы на высоком уровне проводить все формы мероприятий по работе с родителями - родительские собрания, конференции, дискуссионные круглые столы, лекции, видео-презентации. 
Программа, представленная Институтом Семейного Воспитания охватывает множество аспектов обучения, является практико-ориентированной, содержит конкретные методики, которые могут быть использованы при работе с родителями и учениками.

Обучение по программе прежде всего способствует качественной подготовке специалистов образования, повысит уверенность в работе с родителями, разнообразит методы и подходы воспитания, повысит уровень родительской компетентности в вопросах воспитания.

Так, классные руководители, прошедшие курсы с августа по октябре 2019 года , провели родительские собрания в своих классах на тему «Воспитание толерантности», используя разработанный дополнительный материал, полученный онлайн.

Шуманская Т.3., педагог-психолог высшей категории, Екатеринбургский Центр психологопедагогической поддержки несовершеннолетних в своей работе «Воспитание толерантности - основа эффективных межкультурных коммуникаций» представила опыт разработки и внедрения проекта, направленного на формирование установок толерантного поведения учащихся, -«Толерантность и ценности семьи», созданного педагогом-психологом Екатеринбургского муниципального Центра психолого-педагогического сопровождения несовершеннолетних «Диалог» Т. 3. Шуманской и социальным педагогом А. Б. Верещака [6,7]. Толерантность, терпимость к другим становится социально-психологической необходимостью, обеспечивающей стабильность государственности. «Толерантность - это то, что делает возможным достижение мира и ведет от культуры войны к культуре мира», - говорится в Декларации принципов толерантности, принятой Генеральной Конференцией ЮНЕСКО в 1995 году (2).В преамбуле Устава ООН толерантность определяется как необходимость «проявлять терпимость и жить в мире друг с другом, как добрые соседи».

Проблема толерантности актуальна в контексте не только межнациональных, межконфессиональных отношений, но и межличностных и внутрисемейных отношений. Толерантность - это стремление понять позицию другой стороны, способность принять другого, его взгляды и мировоззрение.

Таки образом, одним из важнейших психолого-педагогических условий формирования культуры взаимодействия школы с родителями является толерантность мезжду участниками образовательного процесса. Важнейшую роль в формировании толерантной личности играет семья, и именно в ней ребенок приобретает опыт взаимного уважения, доброжелательного, терпимого отношения к родным, к своим близким. Цели воспитания толерантности достаточно масштабны, они предполагают не только усвоение содержания, но и формирование всех необходимых умений, имеющих отношение к ценности человеческого достоинства. Научить детей принимать и понимать других людей, конструктивно разрешать конфликтные ситуации, взаимодействовать на основе согласия - актуальная задача семьи и школы [ 8].

\section{Вывод}

Таким образом, сотрудничество в организации просвещения родителей и создания психологопедагогичеких условий является актуальным условием формирования культуры личности педагога и родителя. Семье и школе в духе взаимного доверия, уважения, со-развития, , содействовать в организации воспитательного пространства для подрастающего поколения, их родителей, всего общества. Работа Республиканской Конференции «Казахстанские родители XXI века: стань примером своему ребенку», имея практическую направленность в определении точки совместной поддержки, поиска эффективных решений и помощи в сотрудничестве со специалистами комитета по охране прав детей Республики Казахстан и специалистами смежных профессий, показала высокую результативность. Главной ценностью и логичным выводом конференции явилось важность семейного благополучия для воспитания детей. Школе отводится координирующая роль в просвещении через сотрудничество и повышение уровня педагогической культуры родителей и создании психологопедагогических ус

Благодарность. Работа выполнена при поддержке Казахского Национального педагогического университета им. Абая в г. Алматы, Республика Казахстан / Министерства образования и науки Республики Казахстан. Автор выражает благодарность научному руководителю доценту Абдуллаевой Г.О. и профессорско-преподавательному составу кафедры «Педагогика и психоллогия». 
Bekenova Zhibek Amantayevna

Abai University, the Republic of Kazakhstan

E-mail: zh.bekenova@mail.ru

\title{
Psychological and pedagogical conditions for the formation of a culture of interaction between the school and parents in Kazakhstan
}

\begin{abstract}
At the present stage, much attention is paid to the issues of interaction between the family and the school, the formation of culture, its psychological and pedagogical conditions. Along with education and upbringing, the school, as a trust centre for many children and parents, is engaged in the education of all participants in the educational process. Most often, parent-teacher meetings, schools for parents are attended by families with an active civic position, with a high or sufficient level of culture, who find time to be close and listen to their child on time, know how to love their children, are interested in school affairs, are in close contact with class teacher. But their percentage is not high. Analyzing the prevailing socio-pedagogical situations, it became clear that improving the pedagogical culture of parents is one of the important pressing problems. In the new socio-economic conditions, traditional forms of work - pedagogical legal education, pedagogical education in the form of lectures are not effective. New forms and methods of work and cooperation between the family and the school, the exchange of experience in psychological and pedagogical work with parents in a modern school require attention.
\end{abstract}

Key words: education, upbringing, school, parents, family, pedagogical culture.

Ссылка на данную статью: Бекенова Ж.А. (2019) Психолого-педагогические условия формирования культуры взаимодействия школы с родителями в Казахстане. Материалы Международной практической интернет-конференции «Актуальные проблемы науки»/ Materials of International Practical Internet Conference "Challenges of Science”. ISBN 978-601-323-144-0. Выпуск II, 2019. Стр.: 148-152. https:// doi.org/10.31643/2019.029

Список источников и литературы

[1]. Евдокимова С. (2019). Повышение педагогической культуры родителей. Институт Семейного воспитания (г.НурСултан) http://www.ife.kz/

[2]. Концептуальных основах воспитания в условиях реализации Программы «Рухани жаңғыру» на 2019-2024 годы.

[3]. Н.А.Назарбаев (2016). Программа «Рухани Жаңғыру»

[4]. Послание Президента народу Казахстана от октября 2018 г.

[5]. Попова М. Н., Прокопьева М. М. (2015) Социально-педагогическое партнерство школы и семьи как средство повышения родительской компетентности // Современные наукоемкие технологии. -.№ 12 (4). - С. 728-732.

[6]. Кулаковская-Дьяконова А. З., ПрокопьеваМ. М (2016). Этнопедагогические традиции в повышении педагогического потенциала семьи // Педагогическое образование в России: науч. журн. - Екатеринбург,. - № 1. -С. 179-182.

[7]. Семья и школа: проблемы и пути взаимодействия в условиях реализации новых стандартов: учеб.-метод. пособие / под общ. ред. О. А. Щекиной. - СПб.: СПб АППО, 2013. -90 с.

[8]. Шуманская Т. 3 (2013), Воспитание толерантности - основа эффективных межкультурных коммуникаций. «Диалог». 